\title{
'E SE FOR COM VOCÊ?': NARRATIVAS PESSOAIS E MEDO DA VIOLÊNCIA EM CONVERSAÇÕES POLÍTICAS ONLINE SOBRE A MAIORIDADE PENAL
}

\author{
Rafaela Mazurechen Sinderski ${ }^{1}$
}

\begin{abstract}
Resumo
A redução da maioridade penal é debatida há décadas tanto no Congresso Nacional quanto entre cidadãos comuns. Estes últimos costumam se posicionar sobre o tópico em ambientes informais como as redes sociais na internet, participando de conversações que são reconhecidas como políticas e cotidianas e que misturam os temas de interesse público às experiências que provém da vida privada das pessoas. Diante disso, este artigo objetiva analisar tais interações, desenroladas em comentários feitos em páginas de Facebook, a fim de compreender como comentadores utilizam suas histórias e experiências pessoais na construção de narrativas sobre a redução da maioridade penal em conversações políticas online. O estudo é recorte de uma pesquisa mais ampla, que analisou perspectivas temáticas presentes em discussões sobre a redução nas fanpages Quebrando o Tabu, MBL e Senado entre 2015 e 2018. Para este estudo, foi feita uma análise de conteúdo em 1.233 comentários, amostra representativa de 21.352 textos previamente classificados - por análise de conteúdo automatizada com o software Iramuteq - na perspectiva "social". Esses comentários apresentaram discussões sobre a redução considerando elementos como a desigualdade social e o papel da família na dinâmica entre juventude e infrações. A análise mostrou que os comentadores apelam para a emoção e para a insegurança do interlocutor na hora de construir seus discursos. O medo da violência também marcou as conversações, aproximando os resultados da literatura existente sobre posicionamentos dos cidadãos e maioridade penal.
\end{abstract}

Palavras-Chave: Maioridade penal; Conversação política online; Facebook; Análise de conteúdo.

\section{INTRODUÇÃO}

Como assunto sensível e de interesse público (MAIA ET AL, 2017), a redução da maioridade penal é debatida há décadas no Congresso Nacional. Fora desse espaço destinado à discussão sobre questões políticas, o tema tornou-se substrato para conversações cotidianas estabelecidas entre cidadãos comuns, que se posicionam sobre o tópico em ambientes informais como as redes sociais na internet. Diversos autores concordam que, além de serem importantes para a elaboração de argumentos e perspectivas a respeito de assuntos coletivos (CONOVER E SEARING, 2005; KIM E KIM, 2008), as conversações políticas possuem caráter prosaico, combinando questões políticas a narrativas pessoais dos indivíduos (MANSBRIDGE, 1999;

\footnotetext{
${ }^{1}$ Doutoranda em Ciência Política pela Universidade Federal do Paraná (UFPR), mestre em Comunicação pela mesma instituição. Integrante do grupo de pesquisa em Comunicação Política e Opinião Pública (CPOP). E-mail: rafaelasinderski@gmail.com. https://orcid.org/0000-0003-3262-2237
} 
GRAHAM, 2008; MAIA ET AL, 2016, MARQUES E MARTINO, 2016). Diante disso, este artigo objetiva analisar tais interações, desenroladas em comentários feitos em páginas de Facebook, a fim de compreender como comentadores utilizam suas histórias e experiências pessoais na construção de narrativas sobre a redução da maioridade penal em conversações políticas online.

O estudo é recorte de uma pesquisa mais ampla (SINDERSKI, 2020), que analisou perspectivas temáticas presentes em conversações sobre a redução nas fanpages do Movimento Brasil Livre (MBL), Quebrando o Tabu (QT) e Senado Federal (SF) ${ }^{2}$ entre 2015 e 2018. Para este estudo, foi feita uma análise de conteúdo em 1.233 comentários, amostra representativa de 21.352 textos previamente classificados - por análise de conteúdo automatizada com o software Iramuteq na perspectiva "social". Esses comentários apresentaram discussões sobre a redução considerando elementos como a desigualdade social e o papel da família na dinâmica entre juventude e infrações.

A partir deste ponto, o trabalho é dividido em cinco partes: a primeira apresenta o contexto que permeia a discussão sobre a redução da idade penal no Brasil. A segunda trata da definição e das características das conversações políticas online. Na quarta parte, são expostas as estratégias metodológicas da pesquisa, em seguida são discutidos os resultados obtidos na análise e, por fim, são apresentadas as considerações finais do artigo.

\section{A REDUÇÃO DA MAIORIDADE PENAL NO CONTEXTO BRASILEIRO}

A redução da maioridade penal tem sido tema de discussão na sociedade brasileira há muitos anos. Desde $1989^{3}$ - antes mesmo da instituição do Estatuto da Criança e do Adolescente (ECA), que ocorreu em 1990 -, a questão é pauta no Congresso Nacional, acumulando, do período até os dias de hoje, mais de 70 Propostas de Emenda à Constituição na Câmara dos Deputados e no Senado Federal ${ }^{4}$. Ao mesmo tempo, o apoio à medida é constante entre a população (DATAFOLHA, 2004, 2006, 2015, 2019). Para diversos autores (PIMENTEL, 2015; SILVA E OLIVEIRA, 2015; DIAS, 2017, BUDÓ ET AL, 2018), o suporte à mudança costuma estar ligado à divulgação, feita de maneira "alarmista" pelos meios de comunicação, de episódios pontuais de

\footnotetext{
${ }^{2}$ As fanpages apresentam posicionamentos divergentes em relação à redução da idade penal: o MBL se coloca a favor da medida, o QT se posiciona contra e o SF é considerado uma página de posição técnica.

${ }^{3}$ Nessa época, o então deputado federal Nyder Barbosa (MDB) propôs a PEC 35/1989, buscando "tornar plenamente imputáveis os menores de 16 anos, sujeitos às normas de legislação vigente". Disponível em: <https://www.camara.leg.br/proposicoesWeb/fichadetramitacao?idProposicao=169287>. Acesso em: 29/06/2020.

${ }^{4}$ De maio de 1989 a março de 2019 (SINDERSKI, 2020).
} 
violência juvenil. Diante disso, tanto parte da população quanto parte dos parlamentares sustentam a crença de que o número de atos infracionais cometidos por jovens abaixo dos 18 anos está aumentando e que o sistema socioeducativo ${ }^{5}$ é leniente, não sendo uma forma eficaz de responsabilização e, principalmente, de punição (SILVA E OLIVEIRA, 2015; KWEN, 2016; MAIA ET AL, 2017).

A questão é que, para além da segurança pública, a proposta de mudança da idade penal envolve discussões que tangem, também, à educação, exclusão e desigualdade social (ABRAMOVAY ET AL, 2002; ALVES, 2018). Um levantamento do Sinase (2018) aponta que, em 2016, havia 26.450 jovens cumprindo medidas socioeducativas no Brasil. Desses, 96\% eram do sexo masculino e 59\% eram negros. Esse perfil também correspondeu às maiores vítimas de homicídio no país: em 2017, 92,3\% eram homens, 54,5\% eram jovens e 75,5\% eram negras ${ }^{6}$.

Para Abramovay et al (2002), o fato de a violência atingir determinados grupos - como jovens homens negros - com maior intensidade tem relação com a questão da vulnerabilidade social. Silva e Oliveira (2015) destacam que os direitos básicos, como aqueles que buscam garantir educação, saúde e proteção familiar, de muitos adolescentes brasileiros estão longe de ser cumpridos. Isso pode ser notado no âmbito escolar, por exemplo: 36,4\% dos jovens negros entre 15 e 17 anos não estavam cursando o ensino médio em 2017 - em comparação a 23,4\% da juventude branca (IBGE, 2017). Além disso, segundo dados do IBGE (2017), a população preta ou parda representa $75,6 \%$ do grupo que compõe os $10 \%$ mais pobres do país.

Ainda assim, o Brasil parece caminhar em direção à redução da idade penal. Em 2015, a PEC 171/1993 foi aprovada nos dois turnos de votação da Câmara dos Deputados. A proposta prevê a imputabilidade a partir dos 16 anos em casos de crimes hediondos, homicídio doloso e lesão corporal seguida de morte ${ }^{7}$. O presidente Jair Bolsonaro, na época deputado federal pelo Partido Progressista (PP), votou a favor da mudança. Em 2018, ano em que esteve em campanha eleitoral pela Presidência, incluiu a proposta de redução em seu plano de governo como uma medida de segurança pública para conter a criminalidade. Diante dessa conjuntura, importa saber como se desenrolam, entre os brasileiros, as conversações políticas sobre o tema e como o atributo social é inserido nessas discussões, já que ele tende a se aproximar das vivências do cidadão - relacionandose com a desigualdade e com o papel que tem a família e a sociedade nessa problemática. Por isso, a seção seguinte trata das conversações políticas cotidianas e de suas manifestações online.

\footnotetext{
${ }^{5}$ Os adolescentes que cometem atos infracionais são direcionados a cumprir medidas socioeducativas. São sete ao todo, listadas no artigo 112 do ECA.

${ }^{6}$ Dados do Atlas da Violência 2019. Disponível em: 〈https://www.ipea.gov.br/atlasviolencia/>. Acesso em 27/06/2020.

${ }^{7}$ Disponível em: <https://www.camara.leg.br/propostas-legislativas/14493>. Acesso em 28/06/2020.
} 


\section{CONVERSAÇÕES POLÍTICAS COTIDIANAS E SUA PRESENÇA ONLINE}

Entende-se por conversação política cotidiana um tipo de troca comunicativa sobre assuntos de interesse público que se desenrola em espaços informais e contextos rotineiros e que pode oferecer ao cidadão a oportunidade de apresentar seus pontos de vista, elaborar seus argumentos e conhecer a realidade na qual está inserido, sem, contudo, corresponder às pretensões e restrições que envolvem o ato de deliberar (MANSBRIDGE, 1999; KIM E KIM, 2008). Segundo Conover e Searing (2005, p. 270), esse tipo de interação “educa, constrói, filtra, adota, aplica e descarta ideias políticas", sendo saudável para a sociedade democrática (BENNETT, FLICKINGER E RHINE, 2000).

Uma das principais características dessas conversações diz respeito à forte relação que sustentam entre temas políticos, de relevância coletiva, e a experiência pessoal das pessoas que nelas se engajam (GRAHAM, 2008; MAIA ET AL, 2016, MARQUES E MARTINO, 2016). Para Mansbridge (1999), é nas conversações cotidianas que as questões que merecem atenção pública são discutidas pelas pessoas comuns, sem perder de vista a vida privada.

Como ocorrem em ambientes informais, essas manifestações podem se passar na internet e em seus sites de redes sociais, como o Facebook. Esses espaços têm, cada vez mais, abrigado discussões importantes sobre assuntos social e politicamente relevantes (MENDONÇA, SAMPAIO E BARROS, 2016). Contudo, as conversações políticas online nem sempre têm traços democráticos. $\mathrm{Na}$ verdade, são, muitas vezes, radicalizadas e desrespeitosas (CARVALHO, MASSUCHIN E MITOZO, 2018; CERVI, CARVALHO E MASSUCHIN, 2019; RIZZOTTO E BELIN, 2019), principalmente quanto tratam de assuntos polêmicos como a redução da maioridade penal. Por isso, ao analisar os comentários sobre o tópico, este trabalho procura identificar manifestações de hostilidade ao aplicar a variável "agressividade" - a ser apresentada na próxima parte do artigo.

A pesquisa também olha para a forma com que comentadores justificam seus posicionamentos sobre a maioridade penal, a fim de entender se as experiências individuais, de fato, aparecem nas conversações e, se o fazem, como nelas se inserem. Leva-se em consideração os estudos de Rizzotto e Saraiva (2020) e de Massuchin, Mitozo e Carvalho (2017), que encontraram, em suas análises, que narrativas pessoais são usadas como estratégias de argumentação nas redes sociais online. 


\section{ESTRATÉGIAS METODOLÓGICAS}

A fim de compreender como comentadores utilizam suas histórias e experiências pessoais na construção de narrativas sobre a redução da maioridade penal em conversações políticas online, este trabalho aplica uma análise de conteúdo (KRIPPENDORFF, 2004; NEUENDORF, 2016) em 1.233 comentários. Como o artigo é parte de uma pesquisa mais ampla ${ }^{8}$, o corpus é uma amostra representativa $^{9}$ de um grupo de 21.352 comentários retirados de postagens sobre a mudança do limite de imputabilidade, publicadas nas páginas de Facebook do MBL, do Quebrando o Tabu e do Senado Federal entre os anos de 2015 e 2018. Esses textos foram previamente classificados como pertencentes à categoria temática "social"10, o que significa que apresentam discussões sobre a redução considerando elementos como a desigualdade social e o papel da família na dinâmica entre juventude e infrações. A escolha dessa categoria para a presente análise foi guiada pelo entendimento de que esse tipo de abordagem do assunto, que considera elementos sociais enredados nas conversações sobre maioridade penal, permite uma maior inserção de narrativas pessoais dos comentadores nas discussões (SINDERSKI, 2020), já que aciona elementos que mais se aproximam de suas vivências diárias.

A classificação prévia foi realizada por meio de uma análise de conteúdo automatizada (CERVI, 2018, 2019), que utiliza o Iramuteq, interface do pacote estatístico R, para identificar clusters temáticos que oferecem os teores e contextos de determinado corpus textual (CAMARGO E JUSTO, 2013). Depois da identificação dos comentários “sociais" e do cálculo amostral, os 1.233 textos foram submetidos à análise de conteúdo orientada por um livro de códigos adaptado a partir de outros trabalhos que analisam conversações políticas online (MASSUCHIN, MITOZO E CARVALHO, 2017; CARVALHO, MASSUCHIN E MITOZO, 2018). As variáveis e suas categorias são sumarizadas no quadro abaixo.

\footnotetext{
${ }^{8}$ Este artigo é um desdobramento da pesquisa de mestrado da autora.

${ }^{9}$ Com nível de confiança de $97 \%$ e margem de erro de $3 \%$.

${ }^{10}$ Em Sinderski (2020), há a identificação de outras quatro categorias que revelam quais perspectivas temáticas são articuladas nas conversações políticas online sobre redução da maioridade penal: redução punitivista, técnico-carcerária, educacional e moral conservadora.
} 
QUADRO 1 - VARIÁVEIS E CATEGORIAS APLICADAS NA ANÁLISE DOS COMENTÁRIOS

\begin{tabular}{|c|c|c|c|}
\hline VARIÁVEL & COD & CATEGORIA & EXPLICAÇÃO \\
\hline \multirow{5}{*}{$\begin{array}{l}\text { Destinatário do } \\
\text { comentário }\end{array}$} & 1 & $\begin{array}{l}\text { A outro } \\
\text { comentador }\end{array}$ & $\begin{array}{l}\text { Texto direcionado a outro } \\
\text { comentador. Costuma marcar outro } \\
\text { perfil. }\end{array}$ \\
\hline & 2 & $\begin{array}{l}\text { A uma figura ou } \\
\text { instituição } \\
\text { pública/ao } \\
\text { governo }\end{array}$ & $\begin{array}{l}\text { Fala com uma instituição, candidato, } \\
\text { representante ou ex-representante } \\
\text { político. O comentário também pode } \\
\text { ser direcionado ao governo ou a } \\
\text { personalidades conhecidas do } \\
\text { público. }\end{array}$ \\
\hline & 3 & $\begin{array}{l}\text { Aos internautas/à } \\
\text { nação }\end{array}$ & $\begin{array}{l}\text { Dirige-se aos participantes da } \\
\text { conversação em geral. Também pode } \\
\text { ser um comentário dirigido "aos } \\
\text { brasileiros", "à nação". }\end{array}$ \\
\hline & 4 & À página & $\begin{array}{l}\text { Citação textual explícita das páginas } \\
\text { analisadas. }\end{array}$ \\
\hline & 5 & Sem destinatário & $\begin{array}{l}\text { Discute o tema ou fala "sozinho", } \\
\text { sem direcionar seu texto a outros. }\end{array}$ \\
\hline \multirow{4}{*}{ Posicionamento } & 1 & Contra & $\begin{array}{l}\text { Coloca-se contra a redução da } \\
\text { maioridade penal. }\end{array}$ \\
\hline & 2 & A favor & $\begin{array}{l}\text { Coloca-se a favor da redução da } \\
\text { maioridade penal. }\end{array}$ \\
\hline & 3 & Neutro & $\begin{array}{l}\text { Apresenta um posicionamento } \\
\text { "equilibrado" a respeito da questão, } \\
\text { fazendo críticas e elogios, trazendo } \\
\text { pontos positivos e negativos, tudo em } \\
\text { um mesmo texto. }\end{array}$ \\
\hline & 4 & Indefinido & $\begin{array}{l}\text { Quando não é possível definir o } \\
\text { posicionamento do comentador a } \\
\text { respeito do tema. }\end{array}$ \\
\hline \multirow{4}{*}{ Justificação } & 1 & De posição & $\begin{array}{l}\text { Quando não há justificativa. Afirma } \\
\text { uma posição sem nenhum tipo de } \\
\text { argumento. }\end{array}$ \\
\hline & 2 & Interna & $\begin{array}{l}\text { Usa seu próprio testemunho para } \\
\text { defender seus posicionamentos. } \\
\text { Conta histórias pessoais e não se } \\
\text { apoia em fontes externas. }\end{array}$ \\
\hline & 3 & Externa & $\begin{array}{l}\text { Usa fontes externas (dados, links, } \\
\text { notícias, cita fontes conhecidas...) } \\
\text { para manter ou reforçar um } \\
\text { argumento, com informações e dados } \\
\text { que são públicos e podem ser } \\
\text { checados. }\end{array}$ \\
\hline & 4 & Outra & Não há defesa de posicionamento. \\
\hline \multirow[b]{2}{*}{ Agressividade } & 0 & Ausência & $\begin{array}{l}\text { Comentador não expressa } \\
\text { agressividade ao se posicionar. }\end{array}$ \\
\hline & 1 & Presença & $\begin{array}{l}\text { Comentador utiliza palavras de baixo } \\
\text { nível, termos pejorativos, ofensas, } \\
\text { faz ameaças e/ou incita a violência } \\
\text { ao expressar seu ponto de vista. }\end{array}$ \\
\hline
\end{tabular}

FONTE: A autora (2020). 
Para além das variáveis apresentadas, foram consideradas duas ligadas à identificação dos comentários: a variável página, cujas categorias são "MBL", "QT" e "SF", e a variável ano, com as opções “2015”, “2016”, “2017” e "2018”.

A tabela 1 demonstra como a amostra se distribuiu entre os anos e as páginas. As diferenças entre fanpages e períodos correspondem à realidade do que foi coletado ${ }^{11}$. O Quebrando o Tabu contribuiu mais para a formação do corpus, apresentando maior número de comentários classificados como "sociais" dentro do recorte temporal estudado. O ano de 2015 - quando foi aprovada na Câmara dos Deputados a PEC 171/1993 - também é o mais expressivo considerando o volume de material. Só o MBL apresentou comentários sobre a redução da maioridade penal em 2018.

TABELA 1 - DISTRIBUIÇÃO DO CORPUS ANALISADO

\begin{tabular}{l|c|c|c|c|c}
\hline \multicolumn{2}{c|}{} & MBL & $\begin{array}{c}\text { Quebrando o } \\
\text { Tabu }\end{array}$ & $\begin{array}{c}\text { Senado } \\
\text { Federal }\end{array}$ & TOTAL \\
\hline \multirow{2}{*}{2015} & $\mathrm{~N}$ & 44 & 643 & 247 & 934 \\
\cline { 2 - 6 } & $\%$ & 37,9 & 85,2 & 68,1 & 75,8 \\
\hline \multirow{2}{*}{2016} & $\mathrm{~N}$ & 34 & 58 & 68 & 160 \\
\cline { 2 - 6 } & $\%$ & 29,3 & 7,8 & 18,6 & 13 \\
\hline \multirow{2}{*}{$\mathbf{2 0 1 7}$} & $\mathrm{N}$ & 29 & 53 & 48 & 130 \\
\cline { 2 - 6 } & $\%$ & 25,4 & 7 & 13,3 & 10,5 \\
\hline \multirow{2}{*}{2018} & $\mathrm{~N}$ & 9 & 0 & 0 & 9 \\
\cline { 2 - 6 } & $\%$ & 7,4 & 0 & 0 & 0,7 \\
\hline \multirow{2}{*}{ TOTAL } & $\mathrm{N}$ & 116 & 754 & 363 & 1233 \\
\cline { 2 - 6 } & $\%$ & 9,4 & 61,2 & 29,4 & 100 \\
\hline
\end{tabular}

FONTE: A autora (2020).

Expostos os processos metodológicos empregados na pesquisa, a próxima seção apresenta os dados obtidos e discute os resultados à luz da literatura e dos contextos sociopolíticos do período investigado. O corpus classificado foi submetido a testes estatísticos, como qui-quadrado $\left(\chi^{2}\right)$ de Pearson, V de Cramer e resíduos padronizados, para possibilitar uma análise comparativa das características encontradas nas conversações. O primeiro "serve para comprovar se existem diferenças estatisticamente significativas entre duas distribuições quaisquer ou entre casos de uma mesma distribuição" (CERVI, 2014, p. 20), já o segundo permite uma leitura complementar do teste qui-quadrado, apontando para a magnitude do efeito que uma variável possui sobre outra. Por fim, os resíduos padronizados permitiram descobrir quais categorias se relacionaram de forma mais intensa.

\footnotetext{
${ }^{11}$ A coleta foi feita com o auxílio do site Socialfy.
} 


\section{APRESENTAÇÃO E DISCUSSÃO DOS DADOS}

Os resultados encontrados se alinham com a literatura que aponta para a baixa reciprocidade nas conversações políticas online que se desenrolam em sites de redes sociais, o que significa, de forma geral, que os comentadores costumam "monologar", expor seus pontos de vista sem abrir espaço para diálogo e contra-argumentações (CARVALHO, MASSUCHIN E MITOZO, 2018; RIZZOTTO E BELIN, 2019). É o que mostram os dados do gráfico 1, com 72,7\% dos comentários classificados como "sem destinatário". Seus autores estavam preocupados em se posicionar sobre o tema, sem dirigir suas manifestações a quaisquer outras pessoas ou entidades.

\section{GRÁFICO 1 - DESTINATÁRIOS DOS COMENTÁRIOS (\%)}

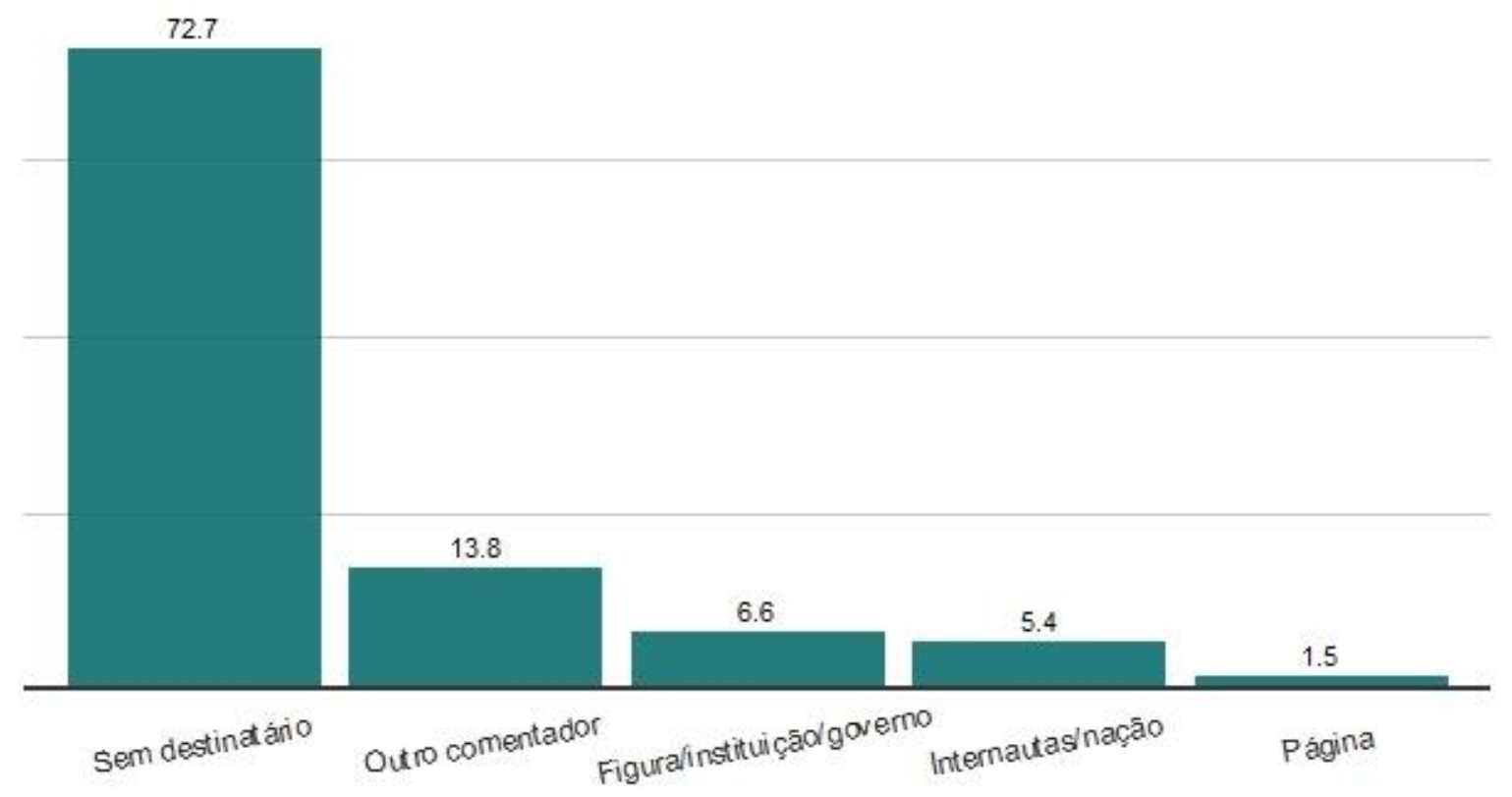

FONTE: A autora (2020).

Os textos direcionados a outros comentadores ocuparam o segundo lugar (13,8\%), seguidos daqueles que interagiram com figuras públicas, instituições políticas ou com o governo $(6,6 \%)$. Os comentários que falaram com os internautas ou brasileiros de maneira geral representaram 5,4\% do corpus, enquanto as manifestações dirigidas às páginas estudadas ficaram restritas a 1,5\%. $\mathrm{O}$ teste de qui-quadrado (tabela 2) mostra que há diferenças estatisticamente significativas na relação entre as variáveis "destinatário" e "página” (com p-valor igual a 0,00) - ou seja, sua distribuição não é 
aleatória. Contudo, segundo o V de Cramer, essa associação é baixa, ocorrendo em apenas 18,6\% dos casos.

TABELA 2 - DESTINATÁRIO DO COMENTÁRIO POR PÁGINA

\begin{tabular}{|c|c|c|c|c|c|c|c|}
\hline & & $\begin{array}{c}\text { Outro } \\
\text { comentador }\end{array}$ & $\begin{array}{c}\text { Figura ou } \\
\text { instituição } \\
\text { política/governo } \\
\end{array}$ & $\begin{array}{c}\text { Internautas } \\
\text { em } \\
\text { geral/nação }\end{array}$ & Página & $\begin{array}{c}\text { Sem } \\
\text { destinatário }\end{array}$ & TOTAL \\
\hline \multirow{3}{*}{ MBL } & $\mathrm{N}$ & 5 & 12 & 6 & 9 & 84 & 116 \\
\hline & $\%$ & 4,3 & 10,3 & 5,2 & 7,8 & 72,4 & 100 \\
\hline & $\mathrm{Rp}$ & $-2,74$ & 1,58 & $-0,12$ & 5,3 & 0,03 & \\
\hline \multirow{3}{*}{$\begin{array}{l}\text { Quebrando o } \\
\text { Tabu }\end{array}$} & $\mathrm{N}$ & 131 & 62 & 47 & 10 & 504 & 754 \\
\hline & $\%$ & 17,4 & 8,2 & 6,2 & 1,3 & 66,8 & 100 \\
\hline & $\mathrm{Rp}$ & 2,65 & 1,77 & 0,94 & $-0,47$ & $-1,87$ & \\
\hline \multirow{3}{*}{$\begin{array}{l}\text { Senado } \\
\text { Federal }\end{array}$} & $\mathrm{N}$ & 34 & 7 & 14 & 0 & 308 & 363 \\
\hline & $\%$ & 9,4 & 1,9 & 3,9 & 0 & 84,8 & 100 \\
\hline & $\mathrm{Rp}$ & $-2,26$ & $-3,44$ & $-1,28$ & $-2,36$ & 2,72 & \\
\hline \multirow{2}{*}{ TOTAL } & $\mathrm{N}$ & 170 & 81 & 67 & 19 & 896 & 1233 \\
\hline & $\%$ & 13,8 & 6,6 & 5,4 & 1,5 & 72,7 & 100 \\
\hline
\end{tabular}

Qui-quadrado: 85,710 (0,00)|V de Cramer: 0,186

FONTE: A autora (2020).

Percebe-se, ao olhar para os resíduos padronizados $(\mathrm{Rp})^{12}$, que o MBL possui uma interação entre comentadores e página acima da que era esperada $(\operatorname{Rp~5,3)}$ caso as distribuições da variável “destinatário" fossem aleatórias nas fanpages analisadas. Uma possível explicação para isso é a natureza do movimento, que é - ou era, durante o recorte temporal da pesquisa - um representante de uma direita antipetista e pró-Bolsonaro, formada pós-protestos de 2013 e defensora de pautas conservadoras (FIRMINO, 2016; PANSARDI, 2018), como a redução da maioridade penal. Por sua origem política e por vocalizar os interesses de determinado grupo, as discussões travadas na fanpage são, sobretudo, relacionadas a contextos e episódios políticos (SINDERSKI E CERVI, 2019). Como um movimento que deve sua força à sua atuação nas redes sociais online (CAVALCANTI, 2017), é compreensível que apresente uma relação mais dinâmica com seu público. Nos comentários analisados, os internautas tenderam a parabenizar ou cobrar o MBL por seus posicionamentos, como nos exemplos a seguir: "Parabéns MBL. Não podemos nos acovardar a cabeças comunistas querendo enganar a sociedade. Lugar de bandido psicopata é na cadeia cumprindo a pena e não em regime semi aberto." [sic] e "Vocês não dão ouvidos as ruas e nem os próprios seguidores", ambos publicados em 2015.

\footnotetext{
${ }^{12}$ Qualquer resíduo acima de 1,96 - ou abaixo de -1,96- deve ser considerado estatisticamente significativo (CERVI, 2014).
} 
O MBL também foi a página que menos apresentou interações entre comentadores ( $\mathrm{Rp}$ 2,74), diferente do que ocorreu com o Quebrando o Tabu. No QT, os internautas tenderam a dialogar mais uns com os outros ( $\operatorname{Rp} 2,65)$, enquanto no Senado Federal as pessoas falaram mais sozinhas $(\operatorname{Rp} 2,72)$.

Em relação ao posicionamento dos comentadores, a maioria $(53,2 \%)$ se colocou a favor da redução (gráfico 2), refletindo o ponto de vista da população brasileira, que tem sido, de forma constante ao longo dos anos, favorável à mudança no limite etário de imputabilidade. Em 2003, 84\% dos brasileiros davam suporte à alteração para dezesseis anos (DATAFOLHA, 2004), taxa que se repetiu em 2006 (DATAFOLHA, 2006). Já em 2015, o apoio alcançou 87\% dos cidadãos (DATAFOLHA, 2015). Nesse mesmo ano, segundo levantamento divulgado pelo DataSenado, 64\% das pessoas acreditavam que os jovens que cometem atos infracionais não são punidos ${ }^{13}$ - ponto de vista muito expressado nos comentários estudados. Por isso, não surpreende que, em 2018, 84\% dos brasileiros ainda apoiavam a redução (DATAFOLHA, 2019).

Foi possível identificar referências às pesquisas de opinião pública nas manifestações de alguns internautas, como mostra o seguinte comentário, postado no Quebrando o Tabu em 2015: "Podem defender o quanto for, eu faço parte desses 87\%, já sofri 157 por 'menores' e sei o quanto é ruim... São sujeito homem pra segurar uma arma, que sejam pra ser presos.” [sic].

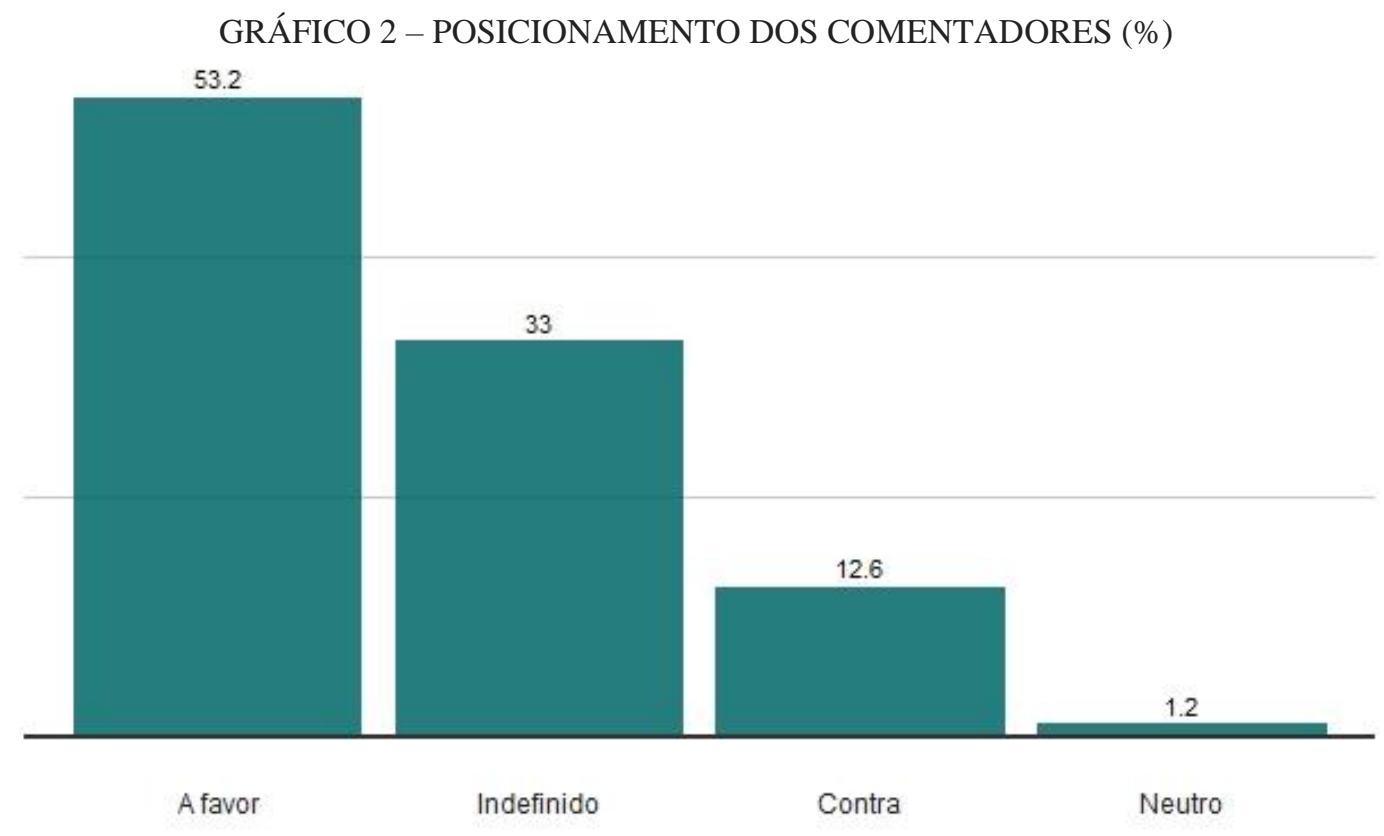

FONTE: A autora (2020).

\footnotetext{
${ }^{13}$ Disponível em: <https://www12.senado.leg.br/noticias/materias/2015/07/16/pesquisa-do-datasenado-aponta-quemaioria-dos-entrevistados-quer-reducao-da-maioridade-penal >. Acesso em: 10/06/2020.
} 
A distância entre a frequência de comentadores que dão suporte à redução da maioridade penal e de comentadores que recusam essa mudança é grande - de 40,6 pontos percentuais. Entre os dois posicionamentos opostos, há uma porcentagem de comentários indefinidos (33\%), cujo ponto de vista sobre o tema não pôde ser identificado. Nesse grupo, encaixaram-se os textos que trataram de violência e juventude considerando a perspectiva social, mas sem se posicionar diretamente sobre a medida de redução. "O que vejo quando eu leio os comentários são pessoas sem fé que falam 'há mas a educação de lá é melhor que a daqui por isso temos que reduzir a maioridade aqui'. Por isso que o Brasil não vai para frente: porque o povo vai para a rua pedir redução na passagem de ônibus mas não vai pedir serviços públicos melhores.” [sic], diz, sobre a comparação Brasil-Estados Unidos, esse comentário postado no Quebrando o Tabu em 2015. As manifestações equilibradas - aqui categorizadas como "neutras" - foram raras, surgindo em apenas 1,2\% do corpus.

$\mathrm{Na}$ tabela 3, pode-se ver que são estatisticamente significativas as diferenças entre "posicionamento" e "página" e que a associação entre as variáveis é de 18,2\%. De forma contraintuitiva, os dados mostram que as manifestações a favor da redução surgem abaixo do esperado no MBL (Rp -3,14). O que supera as expectativas é o posicionamento indefinido (Rp 6,41) na fanpage. Esse resultado se relaciona com o anterior, ligado à interação entre página e internautas: os seguidores se preocupam mais em cobrar o movimento a respeito de ações e posições, deixando, muitas vezes, de explicitar sua própria opinião no comentário.

TABELA 3 - POSICIONAMENTO POR PÁGINA

\begin{tabular}{|c|c|c|c|c|c|c|}
\hline & & Contra & A favor & Neutro & Indefinido & TOTAL \\
\hline \multirow{3}{*}{ MBL } & $\mathrm{N}$ & 1 & 37 & 0 & 78 & 116 \\
\hline & $\%$ & 0,9 & 31,9 & 0 & 67,2 & 100 \\
\hline & $\mathrm{Rp}$ & $-3,55$ & $-3,14$ & $-1,18$ & 6,41 & \\
\hline \multirow{3}{*}{$\begin{array}{l}\text { Quebrando o } \\
\text { Tabu }\end{array}$} & $\mathrm{N}$ & 91 & 413 & 11 & 239 & 754 \\
\hline & $\%$ & 12,1 & 54,8 & 1,5 & 31,7 & 100 \\
\hline & $\mathrm{Rp}$ & $-0,38$ & 0,59 & 0,60 & $-0,62$ & \\
\hline \multirow{3}{*}{ Senado Federal } & $\mathrm{N}$ & 63 & 206 & 4 & 90 & 363 \\
\hline & $\%$ & 17,4 & 56,7 & 1,1 & 24,8 & 100 \\
\hline & $\mathrm{Rp}$ & 2,57 & 0,92 & $-0,19$ & $-2,72$ & \\
\hline \multirow{2}{*}{ TOTAL } & $\mathrm{N}$ & 155 & 656 & 15 & 407 & 1233 \\
\hline & $\%$ & 12,6 & 53,2 & 1,2 & 33 & 100 \\
\hline
\end{tabular}

Qui-quadrado: 81,329 (0,00)| V de Cramer: 0,182

FONTE: A autora (2020). 
A página do Quebrando o Tabu não mostra distribuições diferentes das esperadas para a variável "posicionamento". Mas, numericamente, as manifestações a favor da redução superam em muito as contrárias (tabela 3), mesmo que a fanpage seja contra a medida. Isso pode desafiar o entendimento de que, ao engajar em conversações políticas, os indivíduos preferem se manifestar diante de outros que sustentem perspectivas similares às suas - uma interação entre like-minded people (MOY E GASTIL, 2006). Parece que no caso do QT, internautas buscaram um certo confronto de pontos de vista - considerando que a tabela 2 indica trocas expressivas entre comentadores da página -, diferente do que encontraram Rizzotto, Saraiva e Nascimento (2019) ao pesquisar manifestações sobre o movimento \#EleNão no Twitter: seus resultados apontaram para redes restritas de conversação política, em que o conteúdo era partilhado, principalmente, entre os "já convertidos".

Por fim, para o Senado Federal, há uma presença abaixo da esperada para a categoria “indefinido" (Rp -2,72) e uma presença acima da esperada de manifestações contrárias à mudança no limite de imputabilidade ( $\operatorname{Rp} 2,57)$.

O gráfico 3 mostra a distribuição das categorias de justificação no corpus analisado. Grande parte dos comentadores se preocupou em justificar seu posicionamento de alguma maneira, e a maioria o fez apresentando seu próprio testemunho $(62,8 \%)$ - por vezes até contando suas histórias pessoais.

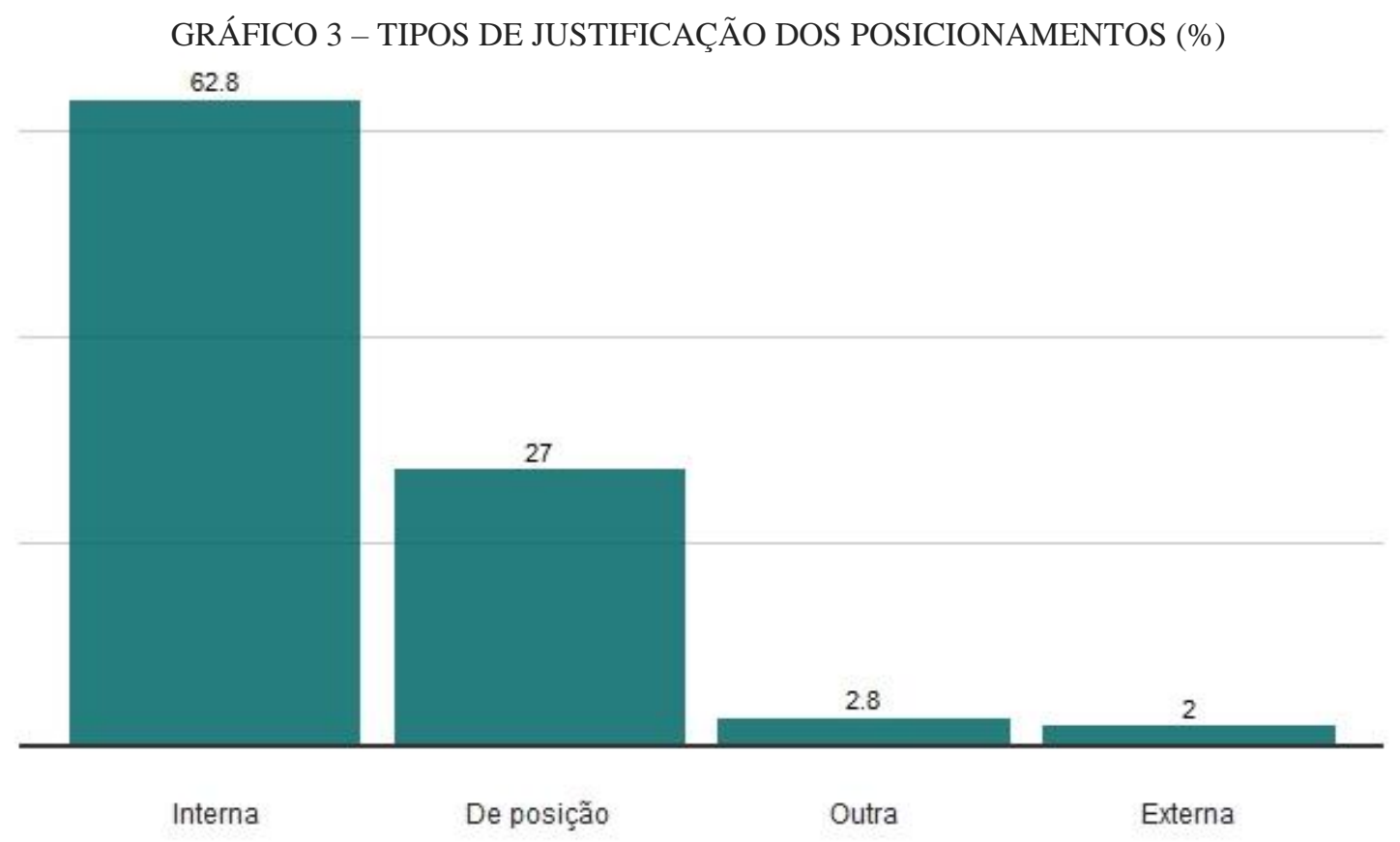

FONTE: A autora (2020). 
As justificativas externas, que apresentaram dados e fontes para embasar opiniões, surgiram em apenas $2 \%$ dos textos. Na categoria "de posição" (27\%), não houve apresentação de argumentos, só a exposição daquilo que o internauta acha.

Nos casos de justificativas internas, os comentadores que apoiaram a medida tenderam a construir a defesa de seus posicionamentos sobre três bases: uma que considera sua experimentação do mundo, outra que se apoia nas experiências de familiares ou conhecidos e uma terceira que ganha força com a apresentação de ameaças. Para o primeiro caso, o argumento geral se relaciona com o contato que o internauta tem ou teve com a violência juvenil; trata-se do que ele vive, vê, ouve e acredita ser a realidade do país a respeito desse tópico. Este é um exemplo: "Difícil pensar em direitos humanos quando alguém menor de idade aponta arma para sua cabeça e leva sua moto com 32 parcelas para pagar. No mínimo gostaria que eles fossem presos, mas em menos de 24 há estavam soltos e assaltando novamente. Passei por isso", afirma o seguidor do Quebrando o Tabu, que postou seu texto no ano de 2015.

Já a segunda situação apresenta narrações de experiências de conhecidos com a violência juvenil. Este texto, também de 2015, feito no Quebrando o Tabu, exemplifica esse tipo de justificativa interna:

\footnotetext{
Nao tem nada haver com ter estudos e possibilidades, vou dar um exemplo. Nessa segunda mataram minha vizinha a facadas e esconderam o corpo embaixo da cama e a filha dela de 8 anos que achou. Agora quem foi? A filha de 16 anos e o namorado, alem de mata-la roubaram dinheiro, celular e o carro dela. Agora te pergunto: a menina era sem estudo, era pobre sem oportunidade? NÃO, pelo contrario tinha tudo que queria mas mesmo assim fez isso. E por esse tipo de jovem que eu sou a favor, a pessoa e mal intencionada e mal carater independente da classe social, cor e idade. [sic]
}

Os comentários que se apoiaram em ameaças para defender sua posição levantaram a possibilidade de grupos e indivíduos contra a redução sofrerem com as infrações de crianças e adolescentes. Eles projetam uma violência futura, que poderia vitimar as famílias daqueles que não concordam com a medida. Nesses casos, foi comum o apelo emocional na construção do argumento, com o uso do recurso "quando acontecer com você..." para dar base ao posicionamento do comentador. "abismado com a hipocrisia do povo.....queria ver o discurso desse povo que é contra, se um fdp de menor assaltar, estuprar ou até matar alguém da familia deles...tem moleque de 16 anos muito maior do que eu........\#páradepalhaçada" [sic], postado no Senado Federal, e "você pensa assim quero ver quando um desses anjinhos matar alguém da sua família ai você vai mudar sua linha de pensamento." [sic], feito no Quebrando o Tabu, ambos publicados em 2015. Esse tipo 
de comentário busca mobilizar os sentimentos de medo, raiva e indignação diante de uma violência possível.

Nos textos "sociais" que defendem a mudança no limite de imputabilidade, o termo "família" esteve muito presente, podendo surgir tanto para tratar das possíveis vítimas da violência juvenil, como nos casos mostrados acima, quanto para apontar possíveis responsáveis por ela. Eles tenderam a definir a família, e não o Estado, como única encarregada da educação dos jovens. Nesse ponto, os internautas diferenciaram a educação escolar da criação e da transmissão de valores éticos e morais que, segundo eles, deveria ocorrer dentro de casa. "A ma criação sinto em dizer, vem de casa, o que uma criança pode respeitar vendo que os responsáveis, quebram, pé fogo estraga, tem atitudes de vandalismo, por conta do que os bandidos parecem a eles. O exemplo tem que começar de casa. então vão presos responder ao delito praticado, quem tem pena leva pra casa pra tentar educar" [sic], publicado em 2015 no Quebrando o Tabu, e "Ei, a responsabilidade de educar é da família e não do Estado, precisou do Estado na hora de fazer filho?", feito no Senado Federal, também em 2015.

Outros argumentos que também se destacaram entre os defensores da redução foram o "leva para casa", que sugere que os jovens autores de infração sejam "adotados" e criados por aqueles que desaprovam a mudança, já que afastar a criança ou adolescente do mundo do crime seria uma tarefa familiar - "Estas pessoa que ficam com dó, tem que levar eles para casa, e faze-los mudar." [sic], texto de 2016, feito no SF - e a compreensão de que o autor da infração já teria plena capacidade de entender suas ações e as consequências que elas trariam. Segundo Lins, Figueiredo Filho e Silva (2016), a imputabilidade penal se forma a partir de dois elementos: (1) o intelectual, que se refere à capacidade do indivíduo de compreender a ilicitude de suas ações; e (2) o volitivo, que se relaciona com a intenção de alcançar, a partir de determinadas ações, um resultado específico. Para alguns dos defensores da redução, o jovem teria pleno controle de ambos os pontos. "Minha mãe sempre me falou, aprenda em casa, para a vida não ter que ensinar, com 16 anos, todo mundo sabe o que é certo e errado, o errado é não querer entender isso !!!!”, postado em 2015 no SF.

Entre quem é contra a redução, prevaleceu o argumento de que a desigualdade social é catalisadora da violência e de que punir não seria uma opção eficaz para mudar esse cenário. Em oposição ao pensamento que predomina nos comentários favoráveis à medida, quem se opõe à mudança acredita que a responsabilidade pela violência é coletiva - do sistema, do Estado, da sociedade - e não individual ou de pequenos grupos - como a família. Este exemplo foi publicado no Senado Federal em 2017: 


\begin{abstract}
Vocês Estado, devem dar condições ao menor e a todo cidadão... vocês são ausentes e ineficientes, sao extremamente corruptos, e cada ato de corrupção rouba um pouco da dignidade e futuro do cidadão. Querem punir a criança, sem dar condições para que ela se torne um cidadão de bem... voces acham mesmo que diminuir a idade criminal vai resolver um problema que voces Estado gera todos os dias?! Voce so toma do cidadao e nao oferece nada em troca! Cadê os principios constitucionais?! Ao invés de dar boas condicoes para que o jovem nao delinqua, voce nao da codicao e ainda quer encher as prisoes de criancas?! Para quê? Para que saiam ainda piores do que entraram? Porque voce Estado também nao ressocializa o preso, o que você faz é criar um deposito humano, no qual faz com que saiam piores e mais desacreditados do sistema do entraram. Você Estado é uma grande piada! [sic]
\end{abstract}

Percebe-se, assim, que uma grande parte dos comentários "sociais" tem uma relação mais forte com as experiências pessoais dos internautas, pois articular questões ligadas à família e ao sentimento de ser vítima de violência dialoga de forma profunda com as subjetividades dos comentadores. A conexão com a vivência das pessoas é uma característica importante das conversações políticas cotidianas (MANSBRIDGE, 1999; GRAHAM, 2008; MAIA ET AL, 2016; MARQUES E MARTINO, 2016) e isso, como se vê, tem se manifestado nos casos estudados.

Essa análise também revelou que o temor que o cidadão tem da violência permeia as discussões sobre redução da maioridade penal nas conversações online, assim como ocorre em outros espaços (CUNHA, ROPELATO E ALVES, 2006; PIMENTEL, 2015; SILVA E OLIVEIRA, 2015; ALVES, 2018). O Brasil soma mais de 60 mil mortes violentas por ano ${ }^{14}$ e, nesse contexto, é comum que o medo influencie a visão dos cidadãos sobre crimes e punições. A população se sente insegura ${ }^{15}$ e acaba por acreditar que penas mais rigorosas são eficientes para inibir atos criminosos, como aponta uma pesquisa feita pela Confederação Nacional da Indústria (2017). Nessa conjuntura, o debate sobre a redução da maioridade penal assume contornos de combate à violência, mesmo em conversações que tratam da questão sob uma perspectiva social.

A tabela 4 mostra que a relação entre as variáveis "justificação" e "página" é significativa, com uma associação baixa, que ocorre em 12,6\% dos casos. Na fanpage do MBL, houve uma presença abaixo da esperada para a categoria "interna” (Rp -2,14). Já as justificativas "de posição" (Rp 2,62) e "externa” (Rp 3,03) surgiram acima do esperado nos comentários da página. Além de expor mais suas opiniões de forma monológica, os comentadores do MBL tenderam a compartilhar mais links na hora de apresentar seus pontos de vista.

\footnotetext{
${ }^{14}$ Dados do Ipea para 2016. Disponível em: <http://www.ipea.gov.br/atlasviolencia/link/7/crimes-violentos-contra-apessoa-registros-policiais>. Acesso em: 10 jun. 2020.

${ }^{15}$ Entre 2016 e $2017,80 \%$ da população afirma ter presenciado situações que "geram insegurança", como agressões e uso de drogas nas ruas (CNI, 2017).
} 
TABELA 4 - TIPO DE JUSTIFICAÇÃO POR PÁGINA

\begin{tabular}{|c|c|c|c|c|c|c|}
\hline & & De posição & Interna & Externa & Outra & TOTAL \\
\hline \multirow{3}{*}{ MBL } & $\mathrm{N}$ & 46 & 60 & 7 & 3 & 116 \\
\hline & $\%$ & 31,3 & 79,1 & 2,4 & 3,2 & 100 \\
\hline & $\mathrm{Rp}$ & 2,62 & $-2,14$ & 3,03 & $-0,11$ & \\
\hline \multirow{3}{*}{$\begin{array}{l}\text { Quebrando o } \\
\text { Tabu }\end{array}$} & $\mathrm{N}$ & 212 & 502 & 12 & 28 & 754 \\
\hline & $\%$ & 28,1 & 66,6 & 1,6 & 3,7 & 100 \\
\hline & $\mathrm{Rp}$ & 0,58 & $-0,54$ & $-0,84$ & 1,58 & \\
\hline \multirow{3}{*}{ Senado Federal } & $\mathrm{N}$ & 75 & 279 & 6 & 3 & 363 \\
\hline & $\%$ & 20,7 & 76,9 & 1,7 & 0,8 & 100 \\
\hline & $\mathrm{Rp}$ & $-2,32$ & 1,99 & $-0,5$ & $-2,21$ & \\
\hline \multirow{2}{*}{ TOTAL } & $\mathrm{N}$ & 333 & 841 & 25 & 34 & 1233 \\
\hline & $\%$ & 27 & 68,2 & 2 & 2,8 & 100 \\
\hline
\end{tabular}

Qui-quadrado: $39,090(0,00) \mid \mathrm{V}$ de Cramer: 0,126

FONTE: A autora (2020).

No Senado Federal, os comentadores sustentaram menos uma justificação "de posição" (Rp -2,32) - que não argumenta, só manifesta a opinião - e apresentaram mais justificativas internas (Rp 1,99). Isso significa que os internautas que discutem sobre a redução da maioridade penal na página costumam apresentar argumentos para sustentar seus pontos de vista, mas tais argumentos são apoiados em suas vivências e percepções sobre o tema, e não em dados ou pesquisas, ainda que, em tese, a fanpage do SF possua manifestações mais técnicas sobre a questão.

Na tabela 6, pode-se ver qual é o tipo de justificação mais comum por posicionamento a respeito da redução. Quem é contra utiliza mais do que o esperado as justificativas internas (Rp 3,23), mas também se preocupa em apresentar argumentos externos ( $\mathrm{Rp} 2,17)$. Já a categoria "de posição" surgiu bem abaixo do esperado em comentários contrários à medida ( $\mathrm{Rp}-5,07)$. Por outro lado, os comentadores favoráveis mostraram ter uma relação menos intensa com a justificação do tipo "externa", já que ela apareceu menos do que era esperado em seus textos (Rp -2). Essa associação entre as variáveis "justificação" e "posicionamento" é significativa e ocorre em quase $20 \%$ dos casos.

TABELA 6 - TIPO DE JUSTIFICAÇÃO POR POSICIONAMENTO

\begin{tabular}{l|c|c|c|c|c|c}
\hline \multicolumn{2}{c|}{} & De posição & Interna & Externa & Outra & TOTAL \\
\hline \multirow{4}{*}{ Contra } & $\mathrm{N}$ & 9 & 139 & 7 & 0 & 155 \\
\cline { 2 - 7 } & $\%$ & 5,8 & 89,7 & 4,5 & 0 & 100 \\
\cline { 2 - 7 } & $\mathrm{Rp}$ & $\mathbf{- 5 , 0 7}$ & $\mathbf{3 , 2 3}$ & $\mathbf{2 , 1 7}$ & $-\mathbf{2 , 0 6}$ & \\
\hline \multirow{3}{*}{ A favor } & $\mathrm{N}$ & 175 & 475 & 6 & 0 & 656 \\
\cline { 2 - 8 } & $\%$ & 26,7 & 72,4 & 0,9 & 0 & 100 \\
\cline { 2 - 7 } & $\mathrm{Rp}$ & $-0,16$ & 1,30 & -2 & $-\mathbf{4 , 2 5}$ & 15 \\
\hline \multirow{3}{*}{ Neutro } & $\mathrm{N}$ & 2 & 13 & 0 & 0 & 100 \\
\hline
\end{tabular}




\begin{tabular}{l|c|c|c|c|c|c}
\hline & $\mathrm{Rp}$ & $-1,01$ & 0,86 & $-0,55$ & $-0,64$ & \\
\hline \multirow{3}{*}{ Indefinido } & $\mathrm{N}$ & 147 & 214 & 12 & 34 & 407 \\
\cline { 2 - 7 } & $\%$ & 36,1 & 52,6 & 2,9 & 8,4 & \\
\cline { 2 - 7 } & $\mathrm{Rp}$ & $\mathbf{3 , 5 3}$ & $-3,81$ & 1,30 & $\mathbf{6 , 7 9}$ & \\
\hline \multirow{2}{*}{ TOTAL } & $\mathrm{N}$ & 333 & 841 & 25 & 34 & 1233 \\
\cline { 2 - 7 } & $\%$ & 27 & 68,2 & 2 & 2,8 & 100 \\
\hline \hline
\end{tabular}

Qui-quadrado: 146,615 (0,00)|V de Cramer: 0,199

FONTE: A autora (2020).

Por fim, 19,2\% do corpus possui alguma expressão de agressividade. A presença dessa característica está relacionada ao emprego de termos pejorativos, de posturas ofensivas, de palavrões, de ameaças explícitas e de incitação à violência, como nos exemplos a seguir: "Avise ao seu ex-amigo ESQUERDINHA ALIENADO, CANALHA, DEFENSOR DE BANDIDOS: FALTA DE OPORTUNIDADE NÃO TRANSFORMA NINGUÉM EM BANDIDO, SEU BURRO. Quem decide ESCOLHER O BEM, ENCONTRA UMA MANEIRA. Quem decide ESCOLHE O MAL, ENCONTRA UMA DESCULPA." [sic], publicado no MBL em 2015; "Nunca vi um condenado voltar a roubar, matar e estuprar, se tá com pena leve pra sua casa, porque se colar na minha morre." [sic], de 2017 no Quebrando o Tabu; e "Deixa de ser ignorante, vá estudar melhor o assunto antes de dar uma opinião dessas. (...) O Brasil é o terceiro país com o maior número de presos e vai acabar se tornando o primeiro rapidinho. Reduzir a maior idade penal da forma como estão propondo só vai piorar a situação. Acorda!’ [sic], postado em 2015 no Senado Federal.

O resultado mostra que são consideráveis os níveis de violência nas conversações online sobre redução da maioridade penal. Outros trabalhos, como os de Carvalho, Massuchin e Mitozo (2018), Cervi, Carvalho e Massuchin (2019) e Rizzotto e Belin (2019), já haviam mostrado que discussões sobre temas políticos nos sites de redes sociais costumam apresentar índices preocupantes de radicalização e desrespeito. Segundo Amossy (2011), a radicalização das conversações tende a estar atrelada a assuntos polêmicos, como é a mudança no limite de imputabilidade, pois eles são discutidos a partir de pontos de vista divergentes, o que, frequentemente, leva ao conflito. Mas o conflito de ideias em si não é o problema. "A questão problemática é o confronto que deixa de ser apenas polêmico para se transformar em ofensivo" (CARVALHO, MASSUCHIN E MITOZO, 2018, p. 904).

A relação entre "agressividade" e "página" é significativa e a associação entre as variáveis é de $14,5 \%$. No MBL, a presença de comportamentos agressivos ficou acima da esperada $(\operatorname{Rp} 3,11)$, enquanto no Senado Federal, esse tipo de manifestação foi menor ( $\mathrm{Rp}-3,20)$. 
TABELA 5 - PRESENÇA DE AGRESSIVIDADE POR PÁGINA

\begin{tabular}{l|c|c|c|c}
\hline \multicolumn{2}{c|}{} & Ausência & Presença & TOTAL \\
\hline \multirow{3}{*}{ MBL } & $\mathrm{N}$ & 79 & 37 & 116 \\
\cline { 2 - 5 } & $\%$ & 68,1 & 31,9 & 100 \\
\cline { 2 - 5 } & $\mathrm{Rp}$ & $-1,51$ & $\mathbf{3 , 1 1}$ & \\
\hline \multirow{2}{*}{$\begin{array}{l}\text { Quebrando o } \\
\text { Tabu }\end{array}$} & $\mathrm{N}$ & 597 & 157 & 754 \\
\cline { 2 - 5 } & $\%$ & 79,2 & 20,8 & 100 \\
\cline { 2 - 5 } & $\mathrm{Rp}$ & $-0,48$ & 1 & 363 \\
\hline \multirow{3}{*}{ Senado Federal } & $\mathrm{N}$ & 320 & 43 & 100 \\
\cline { 2 - 5 } & $\%$ & 88,2 & 11,8 & 1233 \\
\cline { 2 - 5 } & $\mathrm{Rp}$ & 1,56 & $-\mathbf{3 , 2 0}$ & 100 \\
\hline \multirow{2}{*}{ TOTAL } & $\mathrm{N}$ & 996 & 237 & 19,2 \\
\hline
\end{tabular}

Qui-quadrado: 25,966 (0,00) $\mid$ V de Cramer: 0,145

FONTE: A autora (2020).

A tabela 7 acusa a associação entre "agressividade" e "posicionamento", que ocorre em 15,4\% dos casos. Os resíduos padronizados apontam que os comentários daqueles que se colocaram contra a redução da maioridade penal tenderam a ser menos agressivos (Rp -2,71). Já as manifestações a favor da medida mostraram maior relação com a agressividade $(\operatorname{Rp} 3,10)$.

TABELA 7 - PRESENÇA DE AGRESSIVIDADE POR POSICIONAMENTO

\begin{tabular}{|c|c|c|c|c|}
\hline & & Ausência & Presença & TOTAL \\
\hline \multirow{3}{*}{ Contra } & $\mathrm{N}$ & 140 & 15 & 155 \\
\hline & $\%$ & 90,3 & 9,7 & 100 \\
\hline & $\mathrm{Rp}$ & 1,32 & $-2,71$ & \\
\hline \multirow{3}{*}{ A favor } & $\mathrm{N}$ & 495 & 161 & 656 \\
\hline & $\%$ & 75,5 & 24,5 & 100 \\
\hline & $\mathrm{Rp}$ & $-1,51$ & 3,10 & \\
\hline \multirow{3}{*}{ Neutro } & $\mathrm{N}$ & 15 & 0 & 15 \\
\hline & $\%$ & 100 & 0 & 100 \\
\hline & $\mathrm{Rp}$ & 0,82 & $-1,69$ & \\
\hline \multirow{3}{*}{ Indefinido } & $\mathrm{N}$ & 346 & 61 & 407 \\
\hline & $\%$ & 85 & 15 & 100 \\
\hline & $\mathrm{Rp}$ & 0,95 & $-1,94$ & \\
\hline \multirow{2}{*}{ TOTAL } & $\mathrm{N}$ & 996 & 237 & 1233 \\
\hline & $\%$ & 80,8 & 19,2 & 100 \\
\hline
\end{tabular}

FONTE: A autora (2020).

Os testes estatísticos não mostraram diferenças significativas na distribuição das categorias por ano. Isso significa que, em todo o período da amostra, há o mesmo potencial de agressividade, de expressão de um determinado posicionamento ou de certo tipo de justificação, por exemplo. 


\section{CONSIDERAÇÕES FINAIS}

Este trabalho objetivou compreender como comentadores utilizam suas histórias e experiências pessoais na construção de narrativas sobre a redução da maioridade penal em conversações políticas online. O estudo é recorte de uma pesquisa mais ampla, que analisou perspectivas temáticas presentes em conversações sobre a redução nas fanpages do Quebrando o Tabu, MBL e Senado Federal entre 2015 e 2018. Foram 1.233 comentários investigados por meio de uma análise de conteúdo. Os resultados mostraram que, mesmo em discussões que tratam do tema sob uma perspectiva "social", o medo da violência permeia os argumentos relacionados à questão, em especial nas manifestações que são a favor da mudança no limite de imputabilidade.

Além disso, uma grande parte dos comentários (62,8\%) apresentou argumentos para sustentar seus posicionamentos a respeito do tema, utilizando uma justificativa "interna" para tanto. Com esse tipo de justificação, os comentadores apoiaram seus pontos de vista em suas próprias percepções sobre a realidade e/ou na experiência de familiares ou conhecidos. Foi bastante comum a introdução da vivência dos internautas nas conversações políticas online sobre o tópico estudado e muito raro o uso de dados e fontes para embasar opiniões. Outro recurso comum na hora de defender um posicionamento, especialmente o favorável à redução, foi a projeção de uma possível violência no futuro. A ideia do "e se for com você?", da ameaça que pode vir a vitimar as famílias de quem se coloca contra a redução, marcou presença em muitos dos textos analisados. Esse é um elemento que mostra como o medo, a raiva e a indignação foram fortes propulsores de manifestações sobre a maioridade penal.

Para reforçar essa colocação, os dados sobre a variável "agressividade" mostram que os comentários que defenderam a alteração no limite de imputabilidade apresentaram expressões agressivas acima do que era esperado. O mesmo ocorreu com a página do MBL: nela, as manifestações de agressividade superaram o previsto.

Contudo, o MBL não é a fanpage que apresenta um maior número de comentários a favor da redução da maioridade penal, apesar de ser a única que se coloca explicitamente em defesa da causa. O suporte à redução condiz com a maioria dos pontos de vista observados $(52,3 \%)$, e predomina em nas outras duas páginas. Inclusive no Quebrando o Tabu $(54,8 \%)$, que rejeita a possibilidade de diminuição da idade penal, mostrando que há certo conflito de opiniões nessas conversações online. $\mathrm{Na}$ página do Movimento Brasil Livre, a postura mais sustentada foi a indefinida, pois seus seguidores têm, de maneira geral, maior interesse em cobrar o movimento a respeito de suas ações e 
posições, ou em discutir questões e episódios políticos brasileiros, passando apenas lateralmente pela discussão social sobre maioridade penal.

Entre os que se colocam contra a mudança no limite de imputabilidade, houve maior preocupação em justificar posicionamentos, usando tanto argumentações do tipo interna quanto externa. Esse comentários também demonstraram menor presença de agressividade.

A pesquisa se alinha com a literatura que aponta para a falta de diálogo e de reciprocidade nos sites de redes sociais (CARVALHO, MASSUCHIN E MITOZO, 2018; RIZZOTTO E BELIN, 2019), já que 72,7\% dos comentários estudados foram identificados como "sem destinatário". Como o trabalho olha para um recorte específico, há limitações na compreensão das manifestações dos comentadores sobre a redução da maioridade penal. Trabalhos futuros podem ampliar a análise das conversações sobre o assunto para outras páginas, plataformas e períodos de tempo.

\section{REFERENCIAS}

ABRAMOVAY, Miriam et al. Juventude, violência e vulnerabilidade social na América Latina: desafios para políticas públicas. Brasília: UNESCO, BID, 2002.

ALVES, Daniela do Canto. Mídia e redução da maioridade penal: as representações sociais sobre o adolescente em conflito com a lei no telejornalismo da Rede Record. Bauru. Dissertação (Mestrado Acadêmico em Comunicação), Universidade Estadual de São Paulo, 2018.

AMOSSY, Ruth. O intercâmbio polémico em fóruns de discussão online: o exemplo dos debates sobre as opções de acções e bónus no jornal Libération. Comunicação e Sociedade, v. 19, p. 319335, 2011.

BENNETT, Stephen; FLICKINGER, Richard; RHINE, Staci. Political Talk over here, over there, over time. British Journal of Political Science, v. 30, p. 99-119, 2002.

BUDÓ, Marília de Nardin et al. A legitimação do controle do outro: adolescentes e ato infracional nos periódicos jornalísticos Veja, O Globo e Folha de S. Paulo. In: BUDÓ, Marília de Nardin; CAPPI, Riccardo. Punir os jovens: a centralidade do castigo nos discursos midiáticos e parlamentares sobre o ato infracional. Belo Horizonte: Letramento, 2018. p. 97-181.

CAMARGO, Brigido Vizeu; JUSTO, Ana Maria. Tutorial para uso do software IRAMUTEQ, $2018 . \quad$ Disponível em: <http://www.iramuteq.org/documentation/fichiers/Tutorial\%20IRaMuTeQ\%20em\%20portugues_1 7.03.2016.pd>. Acesso em: 14/08/2019. 
CARVALHO, Fernanda Cavassana de; MASSUCHIN, Michele Goulart; MITOZO, Isabele Batista. Radicalização nas redes sociais: comentários no Facebook durante a disputa presidencial em 2014 no Brasil. Análise Social, v. 53, p. 898-926, 2018.

CAVALCANTI, Davi Barboza. Articulação política de grupos brasileiros no séc. XXI: Um estudo sobre as origens e bandeiras do Movimento Brasil Livre e do Vem pra Rua. In: CONGRESSO LATINOAMERICANO DE CIÊNCIA POLÍTICA, 9, 2017, Montevidéu. Anais do $9^{\circ}$ Congresso Latinoamericano de Ciência Política. Montevidéu: ALACIP, 2017.

CERVI, Emerson Urizzi. Análise de dados categóricos em Ciência Política. Curitiba: CPOP, 2014.

CERVI, Emerson Urizzi. Análise de conteúdo automatizada para conversações em redes sociais: uma proposta metodológica. In: ENCONTRO ANUAL DA ANPOCS, 42, 2018, Caxambu. Anais do 42 ${ }^{\circ}$ Encontro Anual da Anpocs. Caxambu: Anpocs, 2018.

CERVI, Emerson Urizzi. Análise de conteúdo aplicada a redes sociais online. In: CERVI, Emerson Urizzi. Manual de Métodos Quantitativos para iniciantes em Ciência Política. v. 2. Curitiba: CPOP, 2019. p. 101-128.

CERVI, Emerson Urizzi; CARVALHO, Fernanda Cavassana de; MASSUCHIN, Michele Goulart. Radicalización y alejamiento entre representantes y representados en las redes sociales digitales. Razón y Palabra, v. 22, n. 103, p. 353-384, 2019.

CONFEDERAÇÃO NACIONAL DA INDÚSTRIA (CNI). Retratos da Sociedade Brasileira Segurança Pública. Brasília: Confederação Nacional da Indústria, ano 6, n. 38, 2017.

CUNHA, Paula Inez; ROPELATO, Raphaella; ALVES, Marina Pires. A redução da maioridade penal: questões teóricas e empíricas. Revista Psicologia: Ciência e Profissão, v. 26, n. 4, p. 646659, 2006.

DATAFOLHA. 84\% votariam a favor da redução da maioridade penal. São Paulo, 2004. Disponível em: <http://datafolha.folha.uol.com.br/opiniaopublica/1227559-84-votariam-a-favor-dareducao-da-maioridade-penal.shtml >. Acesso em: 10/07/2019.

DATAFOLHA. Posição política, opinião sobre o aborto, pena de morte, descriminalização da maconha e maioridade penal: $47 \%$ dos eleitores brasileiros se posicionam à direita. São Paulo, 2006. Disponível em: <http://datafolha.folha.uol.com.br/opiniaopublica/1226779-posicao-politicaopiniao-sobre-o-aborto-pena-de-morte-descriminalizacao-da-maconha-e-maioridade-penal-47-doseleitores-brasileiros-se-posicionam-a-direita.shtml>. Acesso em: 10/07/2019.

DATAFOLHA. 87\% aprovam redução da maioridade. São Paulo, 2015. Disponível em: <http://datafolha.folha.uol.com.br/opiniaopublica/2015/06/1646200-87-aprovam-reducao-damaioridade.shtml>. Acesso em: 10/07/2019.

DATAFOLHA. Maioria quer redução da maioridade penal e é contra posse de armas. São Paulo, 2019. 
<http://media.folha.uol.com.br/datafolha/2019/01/14/15c9badb875e00d88c8408b49296bf94-v.pdf>. Acesso em: 10/06/2020.

DIAS, Maite Nora Blancquart Mendes. Maioridade Penal em pauta: medo e punição na imprensa. Niterói. Dissertação (Mestrado em Mídia e Cotidiano), Universidade Federal Fluminense, 2017.

FIRMINO, Gustavo Casasanta. Conservadorismo liberal e classes médias: uma análise do 'Vem Pra Rua' e do 'Movimento Brasil Livre'. In: SEMINÁRIO DO TRABALHO: TRABALHO, CRISE E POLÍTICAS SOCIAIS NA AMÉRICA LATINA, 10, 2016, Marília. Anais do X Seminário do Trabalho: trabalho, crise e políticas sociais na América Latina. Marília: Unesp, 2016.

GRAHAM, Todd. Needles in a haystack: a new approach for identifying and assessing political talk in non-political discussion forums. Javnost - The Public, v. 15, n. 2, p. 17-36, 2008.

IBGE. Coordenação de Trabalho e Rendimento. Pesquisa Nacional por Amostra de Domicílios. Rio de Janeiro: IBGE, 2017.

KIM, Joohan; KIM, Eun Joo. Theorizing dialogic deliberation: everyday political talk as communicative action and dialogue. Communication Theory, n. 18, p. 51-70, 2008.

KRIPPENDORFF, Klaus. Content Analysis: An Introduction to its Methodology. London: Sage Publications, 2004.

KWEN, Nara Josepin. O debate da maioridade penal no Congresso Nacional: mapeamento das propostas legislativas. São Paulo. Dissertação (Mestrado em Direito), Fundação Getúlio Vargas, 2016.

LINS, Rodrigo; FIGUEIREDO FILHO, Dalson; SILVA, Lucas. A redução da maioridade penal diminui a violência? Evidências de um estudo comparado. Opinião Pública, v. 22, n. 1, 2016.

MAIA, Rousiley et al. Sobre a importância de se examinar diferentes ambientes on-line em estudos de deliberação a partir de uma abordagem sistêmica. In: MENDONÇA, Ricardo Fabrino; SAMPAIO, Rafael Cardoso; BARROS, Samuel Anderson Rocha. Deliberação on-line no Brasil: entre iniciativas de democracia digital e redes sociais de conversação. Salvador: EDUFBA, 2016.

MAIA, Rousiley et al. Conversação e Deliberação sobre questões sensíveis: um estudo sobre o uso das razões que circulam nos media. Galaxia, v. 34, p. 55-72, 2017.

MANSBRIDGE, Jane. Everyday talk in the deliberative system. In: MACEDO, Stephen. Deliberative politics: essays on democracy and disagreement. New York: Oxford University Press, p. 211-239, 1999.

MARQUES, Ângela Cristina Salgueiro; MARTINO, Luís Mauro Sá. A politização da conversação cotidiana e suas relações com processos deliberativos. In: ENCONTRO DA ASSOCIAÇÃ̃O BRASILEIRA DE CIÊNCIA POLÍTICA, 10, 2016, Belo Horizonte. Anais do $10^{\circ}$ Encontro da Associação Brasileira de Ciência Política. Belo Horizonte: ABCP, 2016. 
MASSUCHIN, Michele Goulart; MITOZO, Isabele Batista; CARVALHO, Fernanda Cavassana de. Eleições e debate político on-line em 2014: os comentários no Facebook do jornal O Estado de S. Paulo. Revista Brasileira de Ciência Política - RBCP, p. 295-320, 2017.

MENDONÇA, Ricardo Fabrino; SAMPAIO, Rafael Cardoso; BARROS, Samuel Anderson Rocha. Deliberação on-line no Brasil: entre iniciativas de democracia digital e redes sociais de conversação. Salvador: EDUFBA, 2016.

MOY, Patricia; GASTIL, John. Predicting deliberative conversation: The impact of discussion networks, media use, and political cognitions. Political Communication, v. 23, n. 4, p. 443-460, 2006.

NEUENDORF, Kimberly. Variables and Predictions. In: NEUENDORF, Kimberly. The content analysis guidebook. London: Sage Publications, 2016. p. 95-110.

PANSARDI, Marcos Vinícius. O 'Moderno Príncipe Conservador': o MBL e o novo projeto político da direita brasileira. Estudios Latinoamericanos, n. 42, p. 75-88, jul./dez. 2018.

PIMENTEL, Gabriela Hauber. O papel das emoções na deliberação: o debate sobre a redução da maioridade penal no Brasil. Belo Horizonte. Dissertação (Mestrado em Comunicação Social). Universidade Federal de Minas Gerais, 2015.

RIZZOTTO, Carla; BELIN, Luciane. DEBATE ALÉM DA FRONTEIRA: características deliberativas da conversação de brasileiros sobre a [não] descriminalização do aborto na Argentina. In: CONGRESSO DA ASSOCIAÇÃO BRASILEIRA DE PESQUISADORES EM COMUNICAÇÃO POLÍTICA, 8, 2019. Anais do VIII Congresso da Associação Brasileira de Pesquisadores em Comunicação Política . Brasília: Compolítica, 2019.

RIZZOTTO, Carla Candida; SARAIVA, Aléxia. Violência de gênero em debate: uma análise das conversações sobre a lei do feminicídio na fanpage do Senado Federal. Intexto, n. 49, p. 249-269, 2020.

RIZZOTTO, Carla, SARAIVA, Alexia; NASCIMENTO, Louize. \#ELENÃO: conversação política em rede e trama discursiva do movimento contra Bolsonaro no Twitter. In: ENCONTRO ANUAL DA ASSOCIAÇÃO NACIONAL DOS PROGRAMAS DE PÓS-GRADUAÇÃO EM COMUNICAÇÃO, 27, 2019. Anais do $27^{\circ}$ Encontro Anual da Associação Nacional dos Programas de Pós-Graduação em Comunicação. Porto Alegre: Compós, 2019.

SILVA, Enid Rocha Andrade; OLIVEIRA, Raissa Menezes de. O Adolescente em conflito com a lei e o debate sobre a redução da maioridade penal: esclarecimentos necessários. Brasília: Instituto de Pesquisa Econômica Aplicada - IPEA, 2015.

SINDERSKI, Rafaela Mazurechen. Conversação política online sobre a redução da maioridade penal: uma análise comparativa das fanpages Quebrando o Tabu, Movimento Brasil Livre e Senado Federal entre 2015 e 2018. Curitiba. Dissertação (Mestrado em Comunicação). Universidade Federal do Paraná, 2020. 
SINDERSKI, Rafaela Mazurechen; CERVI, Emerson Urizzi. Conversação política na fanpage do Movimento Brasil Livre: uma análise das discussões sobre a redução da maioridade penal entre 2015 e 2018. Teoria \& Pesquisa (online), v. 28, p. 75-96, 2019. 